\title{
La dualidad en la ficción televisiva fantástica. Análisis ideológico de The Passage y The Society
}

The duality in fantastic TV fiction. An ideological analysis of The Passage and The Society

\section{A dualidade na ficção de TV fantástica. Uma análise ideológica de The Passage e The Society}

Mayte Donstrup, Universidad de Sevilla, Sevilla, España (mdonstrup@us.es)

Cristina Algaba, Universidad de Sevilla, Sevilla, España (cperezdealgaba@us.es)

RESUMEN | La dualidad o tema del doble emerge de la ficción literaria, cinematográfica y televisiva como parte de una construcción mental mítica presente en la psique del hombre. Este trabajo se propone estudiar cómo se refleja esta dualidad en la ficción televisiva actual a través del análisis crítico del discurso ideológico de dos series: The Society (Netflix, 2019) y The Passage (Fox, 2019). Los resultados indican que ambas series se encuentran permeadas con valores conservadores. Con esta aportación se visibiliza la presencia de elementos ideológicos en las series de televisión del género fantástico, así como la importancia de su estudio y comparación con otras producciones de ficción dentro de un periodo de emisión específico.

PALABRAS CLAVE: series de televisión; ideología; narrativa fantástica; estudios culturales; dualidad. 
ABSTRACT | Duality emerges from literary or audiovisual fiction as part of a mythical mental construct present in the human psyche. This research aims to study how this dualism is reflected in contemporaneous television fiction through the critical analysis of the ideological discourse of two TV series: The Society (Netflix, 2019) and The Passage (Fox, 2019). The results indicate that both series are permeated with conservative values. This contribution makes visible the presence of ideological elements in fantastic TV series, as well as emphasizes the importance of their study and comparison with other TV productions within a specific broadcasting period.

KEYWORDS: TV series; ideology; fantastic narrative; cultural studies; duality.

RESUMO | O dualismo ou dualidade emergem da ficção literária, do filme e da televisão como parte de uma construção mental mítica presente na psique do homem. Este artigo tem como objetivo estudar como esse dualismo se reflete na ficção televisiva de hoje através da análise crítica do discurso ideológico de duas séries: The Society (Netflix, 2019) e The Passage (Fox, 2019). Os resultados indicam que ambas as séries estão permeadas de valores conservadores. Essa contribuição faz com que a presença de elementos ideológicos nas séries televisivas do gênero fantasia, bem como a importância de seu estudo e comparação com outras produções de ficção dentro de um período de emissão específica.

PALAVRAS-CHAVE: séries de TV; ideologia; narrativa de fantasia; estudos culturais; dualidade. 


\section{INTRODUCCIÓN}

Las series de televisión constituyen un interesante objeto de reflexión sobre la sociedad que expresan y en la que se insertan. En este sentido, el visionado de series puede establecer un vínculo con el mundo de la política (Nærland, 2019); política no en el sentido estricto, es decir, referida de forma rigurosa al significado profesional del término, sino al discurso que mantiene la sociedad sobre cómo organizarse y cómo identificarse a sí misma (Diken \& Laustsen, 2017). En este caso, todos somos sujetos políticos y las series de televisión no requieren hacer mención expresa de organizaciones políticas específicas para expresar ideas ligadas a un determinado espectro ideológico. Tal es así que se ha comprobado que la cultura popular, en sus diversas formas, ofrece a los jóvenes puntos de identificación con los asuntos de ámbito nacional e internacional de una manera especial; pues parecen establecer conexiones entre lo privado y lo político con mucha más facilidad mediante la cultura popular (Scott, Street, \& Inthorn, 2011).

Por lo tanto, examinar los discursos que las series de televisión diseminan no es baladí, puesto que su combinación de discurso mediático, conocimiento experiencial y sabiduría popular las convierten en un recurso potencial (van Zoonen, 2007) de transmisión de valores sociales. Además, como afirma Henry Jenkins (2000), el texto juega un rol central en la configuración de su recepción pues, aunque la audiencia se pueda apropiar del contenido textual, existe una autoridad del texto y del autor difícil de evadir; y aunque la cultura de masas pueda contener en su seno discursos que ocupen todo el espectro ideológico (Pineda, Fernández-Gómez, \& Huici, 2018), cabe destacar que la mayoría de los que pertenecen al circuito comercial mainstream son de tinte conservador (Chomsky \& Herman, 2009).

Las series objeto de análisis de esta investigación son The Society (Netflix, 2019) y The Passage (Fox, 2019). En primer lugar, en este trabajo se realizará un repaso por las teorías y los conceptos relacionados con ideología y la dualidad en lo fantástico, lo que nos permitirá estudiar cómo intervienen en la narrativa de las mencionadas ficciones televisivas. Posteriormente, se elaborará una discusión de los resultados obtenidos con diferentes investigaciones sobre ficción fantástica contemporánea. La consecución de los objetivos planteados nos permitirá responder a una principal cuestión: ¿cómo se representa la naturaleza humana en The Passage y en The Society?

\section{FANTASÍA E IDEOLOGÍA}

Los textos fantásticos, según destacan Ina Batzke, Eric C. Erbacher, Linda M. Heß y Corinna Lenhardt (2018), reflejan, fortalecen o confrontan las ideologías culturales. En este sentido, como señala Frédéric Martel (2011), en el siglo XXI, las producciones culturales de los Estados Unidos suponen una vía para influir 
en los asuntos internacionales y mejorar su imagen a través del ejercicio de un soft power ${ }^{1}$, gracias a la distribución de su contenido que permite la globalización. Dicha observación hace que analizar qué tipo de contenidos ofrece una industria audiovisual como la estadounidense, marcada por esa búsqueda de ejercer un poder blando en el resto del mundo, sea una cuestión interesante. En este sentido, el género fantástico moldea, al igual que otros géneros cultivados dentro de la industria hollywoodense, ese American mythos que trasciende a la audiencia internacional (Johnson-Smith, 2005).

La televisión, más que cualquier otra tecnología, materializa la inmemorial fantasía humana de trascender los límites del tiempo y el espacio en la búsqueda de otra realidad (Loshitzky, 1996). Más específicamente, insertas en este formato, las series de televisión se han convertido en su producto emergente e ignorarlas sería obviar uno de los más importantes modos de contar historias de nuestro tiempo (Kallas, 2014). Al igual que la función social del mito (Huici, 1996), las series televisivas pueden implicar la adhesión a unos determinados valores, la explicación de ciertas preguntas que se hace sobre sí misma la sociedad y la institución de unos determinados usos y costumbres. Así, como argumenta Milly Buonanno (1999), estas cumplen un rol fundamental en la comunidad: en primer lugar, las series son fabuladoras, hablan del espectador y sobre él, aportando experiencias de la vida cotidiana. En segundo lugar, son familiarizadoras: construyen un sentido común de la sociedad y aportan valores comunes a sus miembros. Por último, sirven como mantenimiento de la comunidad, considerando aceptar los elementos novedosos paulatinamente, pero siempre rechazando todo aquello considerado como radical.

Por su parte, las narraciones seriales, como todo relato creado por el ser humano, son susceptibles de portar valores ideológicos, entendiendo ideología como la autorepresentación que se hace de sí mismo el ser humano: sus valores y características que hacen que se relacione con su entorno de una determinada forma (van Dijk, 2000). Es decir, como señala el autor, "una ideología es un esquema que sirve a sus propios intereses para la representación de Nosotros y Ellos como grupos sociales" (2000, p. 95). Por lo tanto, "tienen el formato de un esquema de grupo, o al menos el formato de un esquema de grupo, que refleja nuestros intereses sociales, económicos, políticos o culturales fundamentales" (2000, p. 95). La ideología es

1. El soft power o poder blando hace referencia a la persuasión a través de la fascinación que emite una nación (Nye, 2005). En este sentido, la producción audiovisual que se comercializa ejerce un rol influyente en el resto de los países que consumen estos productos; cítese como ejemplo la industria de contenidos estadounidense. 
un elemento social que impregna con diferentes niveles todos los sustratos de la sociedad: uno de ellos, las series de televisión.

Enmarcado en el género fantástico, el aspecto ideológico se adhiere a las ficciones con diversas temáticas, portadoras de connotaciones que evocan en el espectador la aceptación o rechazo de las ideas que se le presentan. Además, se observa en el terreno creativo la versatilidad que presenta el género fantástico para jugar con unidades conceptuales del ámbito político e ideológico a través de la alteridad de los elementos que conforman la realidad del espectador. La irrupción de lo fantástico, como señala Teodosio Fernández,

[...] no tiene por qué residir en la alteración por elementos extraños de un mundo ordenado por las rigurosas leyes de la razón y la ciencia. Basta con que se produzca una alteración de lo reconocible, del orden o desorden familiares. Basta con la sospecha de que otro orden secreto (u otro desorden) puede poner en peligro la precaria estabilidad de nuestra visión del mundo. (2001, pp. 296-297)

A continuación, abordaremos las posibilidades del género fantástico para introducir ese desorden o alteración de lo conocido mediante la aplicación de determinados ejes temáticos, centrándonos en la dualidad o tema del doble como una de las temáticas principales para inducir a la audiencia a la reflexión sociopolítica.

\section{La dualidad como temática de lo fantástico}

La ficción fantástica, como señala Louis Vax, "se deleita en presentarnos a hombres como nosotros en presencia de lo inexplicable, pero dentro de nuestro mundo real" (1965, p. 6). Estos fenómenos inexplicables, sin embargo, no suelen carecer de sentido dentro de la narración. Al contrario, como destaca Gérard Lenne, el esquema fantástico "convoca al sentido" y lejos de ser "una estructura vacía", esta siempre es "significante, deliberada o fortuitamente" (1974, p. 45).

Para la construcción de estas significaciones, la detección de determinadas temáticas e iconografías dentro del género favorece el estudio de la evolución de su significado o representación dentro de las distintas producciones y épocas. El "abordaje tematológico nos ayudará a entender los modos en que la cultura mediática, mediante sus figuraciones narrativas, contribuye a construir no sólo la memoria del pasado, sino las proyecciones del porvenir" (Chillón, 2000, p. 154).

En El cine fantástico y sus mitologías (1970), Lenne diferencia cinco ejes temáticos principales - la dualidad o tema del doble, del mal, la monstruosidad, el antropomorfismo y las alteraciones el cuerpo humano-, que serán revisados posteriormente por otros autores como Joan Bassa y Ramón Freixas (1993), quienes realizan un trasvase de estos temas al género de ciencia ficción, incorporando fruto 
de esta revisión dos nuevos ejes temáticos en la citada taxonomía: la supervivencia y los recorridos iniciáticos o viajes, tanto por el espacio como por el tiempo. Ambos ejes son extrapolables al género fantástico, especialmente en materia de la concepción del viaje como un recorrido iniciático o viaje de aventuras, y la supervivencia, fruto de la alteración o irrupción de lo extraño en lo conocido. Derivadas de la producción literaria de lo fantástico, estas temáticas también serán trasvasadas al contenido de ficción televisiva del género, como recogen otros estudios sobre el desarrollo del género fantástico y de ciencia ficción dentro del cine y la televisión (Telotte, 2008, 2014; Geraghty, 2009; Seed, 2011; Barceló, 2015). Como señalan João Antonio Nogueira Ramos Neto y Marcio Markendorf (2018), a través de la reiteración dentro de cada género y de cada medio de determinados temas e iconografías se contribuye a la formación de un imaginario colectivo compartido por la audiencia.

De entre los temas enunciados, la presencia de la dualidad dentro de este imaginario colectivo es un elemento común en el binomio monstruosidad/ normalidad, normalidad/anormalidad o bien vs. mal. "En definitiva, puede decirse que la dualidad supone un elemento presente en la naturaleza humana y ello se manifiesta en narraciones míticas y religiosas desde el comienzo de los tiempos" (Pérez de Algaba Chicano \& Rubio-Hernández, 2015, p. 188), siendo ampliamente estudiado como "modelo mental mítico" que se configura en la psique del ser humano como un "mecanismo universal original" (López Saco, 2008, p. 98). Dentro de los binomios que se detectan en las construcciones narrativas de lo fantástico, la dicotomía bien vs. mal radica en la necesidad de los dos ejes para comprender la presencia del "otro". La existencia del mal no se comprende si no es enfrentada a su imagen invertida, el bien. Bassa y Freixas (1993) señalan que el mal será equiparado a desorden, miedo, inquietud o caos producido por agentes perturbadores encarnados en torno a dos vías fundamentales que se corresponden, en un sentido general, con las dos vertientes de peligro diferenciadas por Lenne (1974).

En la primera vía, el peligro o representación del mal llega de otra parte, es algo externo al individuo. En este sentido, seres propios de lo fantástico como los monstruos, mutantes, gigantes o alienígenas romperán con lo hasta ahora conocido o considerado normal dentro de una sociedad. Sin embargo, esta dualidad se corresponde, en un gran número de ocasiones, con la proyección de nosotros mismos bajo distintas perspectivas, plasmándose en personajes propios de lo sobrenatural. Esta proyección, sin embargo, siempre es presentada dentro del relato de ficción como el "otro", relegando en él toda la responsabilidad sobre el deterioro de nuestra sociedad o del cambio generado en ella.

Una segunda vía se centra en los peligros que vienen del hombre o que se vuelven contra él, siendo los terrícolas los responsables de la amenaza propagada, encarnada 
en figuras como la del científico o las propias instituciones gubernamentales que se venden al enemigo. En otras ocasiones, el individuo sentirá que está siendo castigado por algo derivado de su mala praxis (individual o como sociedad), como veremos más adelante en The Society.

El enfrentamiento o superación de estos peligros integra directamente el eje temático de la supervivencia, que puede presentarse de forma individual, "representada en la lucha del individuo o de un pequeño grupo por la supervivencia en un mundo hostil, intentando el retorno a la civilización o su reconstrucción" (Bassa \& Freixas, 1993, p. 55). En esta primera vertiente, el grupo de supervivientes será guiado por un "héroe positivo" que los ayudará a superar "los peligros procedentes de restos disidentes de la sociedad" o de horribles mutaciones biológicas "hacia los nuevos horizontes de la tierra prometida, donde la sociedad volverá, de nuevo, a renacer" (Bassa \& Freixas, 1993, p. 55).

La supervivencia colectiva, por su parte, se vislumbra cuando toda una comunidad se enfrenta a una amenaza de orden biológico, geológico o extraterrestre. La sociedad, como un solo hombre, se levantará en armas bajo el liderazgo de uno o varios héroes positivos de ese momento, quienes se encargarán de dirigir la batalla contra aquel elemento que desestabiliza su seguridad o supervivencia. Dada la fecha de su obra, Bassa y Freixas enfatizan en este tipo de situaciones la confianza del pueblo en sus gobernantes para solucionar sus conflictos, vehiculando la victoria a sus eficientes técnicos y científicos: "es el triunfo de la casta burocrática" (1993, p. 55). Asimismo, señalan que esta vertiente colectiva presenta rasgos menos radicales que la individual, al encontrarse la humanidad no ante una catástrofe consumada, sino ante el aviso de su posible advenimiento.

Con respecto al origen de la amenaza, Bassa y Freixas se centran en el peligro provocado por agentes externos, reduciéndolo a "dos máscaras: los extraterrestres y la invasión biológica” (1993, p. 57). En otras ocasiones, el peligro viene del hombre, peligrosidad que Gérard Lenne (1974, pp. 71-74) subdivide en tres apartados:

a. El primero engloba las alteraciones experimentadas por el hombre de forma involuntaria, que se producen por vía externa, como es el caso de los zombis $u$ hombres sin identidad. Aparte de otras figuras como el hombre como ente salvaje o el no-muerto, la ficción del siglo XXI cultivará los cambios vinculados a mutaciones o poderes extrasensoriales no controlados por los individuos que los manifiestan.

b. Debe señalarse también la amenaza proveniente del hombre civilizado, categoría que comprende la persecución y el intento de aniquilación de la 
que son objeto los protagonistas de la serie o película en el momento de su huida o enfrentamiento con la sociedad de la que forman parte.

c. En el estadio máximo de peligro interno estaría toda la producción protagonizada, casi siempre, por un científico con intencionalidad de Demiurgo que reúne en una sola persona la locura y el genio, aderezados con crueldad y sadismo. A través de The Passage se abordará la figura del científico como introductor de lo sobrenatural y de la amenaza externa bajo una pandemia creada por él.

Los diferentes tipos de amenaza propician una reacción defensiva en la humanidad, que una vez que vence el riesgo, permite al género humano que reafirme su esencia y supremacía:

En la temática de la supervivencia, el eje central de actuación es el Hombre, en cuanto es objeto de agresiones que perturban su status adquirido, llevándole hacia una posible pérdida del mismo. Es una batalla que libra el Hombre contra una serie de elementos perturbadores: se dirime la supremacía -supervivencia- ideológica y física. (Bassa \& Freixas, 1993, p. 57)

En definitiva, los peligros y las amenazas que confrontan valores bajo esta dualidad imperante en el género serán fundamentales para articular un discurso ideológico que cargue de significación el texto fantástico.

\section{METODOLOGÍA}

A continuación, estudiaremos la irrupción de lo extraño y el eje temático de la dualidad a través de dos ficciones televisivas de reciente creación: The Society (Netflix, 2019) y The Passage (Fox, 2019). La muestra ha sido escogida según su estreno (primera temporada en el año 2019) y el rol protagónico de personajes en edad de maduración (adolescencia). En este sentido, en la etapa de socialización las personas se encuentran desarrollando su identidad (Myers, 2008). Dicha característica nos permitirá analizar un punto de discusión de toda ideología: la naturaleza humana innata.

El estudio de las dos series televisivas será realizado aplicando un Análisis Crítico del Discurso (ACD), de modo que se observará el discurso como una práctica social mediante la cual se reflejan las connotaciones ideológicas (van Dijk, 2000). Por su parte, se debe señalar que la enunciación no tiene por qué limitarse a la palabra, siendo posible el examen de todo aquello que tenga un carácter semiótico, como las imágenes (Wodak, 2003). En consecuencia, este artículo combinará dos áreas de estudio: el Análisis Crítico del Discurso (van Dijk, 2000; van Dijk, 2009) 
y el análisis audiovisual (Casetti \& di Chio, 2010). El primero será utilizado para determinar la construcción del discurso político en la ficción (es decir, establecer a través de la semiótica de los personajes los elementos ideológicos de la serie). El análisis audiovisual, por su parte, fijará unos parámetros principales para el estudio del producto ficcional y la estructura del género, siendo especialmente relevante el estudio de las temáticas, personajes y espacios que pueblan los dos productos de ficción. Así, se tomarán los presupuestos de la descomposición del material audiovisual para una mejor descripción e interpretación; una fragmentación en la que serán analizadas diferentes secuencias, es decir, unidades de contenido dentro del todo que tienen su propia historia dentro de la temática general del producto audiovisual (Casetti \& di Chio, 2010). En consecuencia, se valorarán especialmente "[l] as reacciones de los personajes, su manera de hablar o de moverse, [pues estos] son recursos esenciales para la exteriorización de su psicología y su caracterización" (Galván Fajardo, 2007, p. 3).

\section{LA DUALIDAD EN LA FICCIÓN FANTÁSTICA TELEVISIVA: ANÁLISIS IDEOLÓGICO DE THE PASSAGE Y THE SOCIETY}

The Society: la exploración de la anormalidad como reconstrucción del sistema

¿Qué pasaría en una sociedad si desaparecen las personas que velan por mantener en orden y en buen funcionamiento el sistema que la sustenta? Esta cuestión sirve como premisa del drama de misterio adolescente de diez episodios The Society. En ella, la misteriosa irrupción de un olor nauseabundo en la pequeña localidad de West Han (Connecticut) deriva en el traslado, por decisión del Gobierno Federal, de los estudiantes de secundaria a un viaje de campamento mientras se resuelve el problema. No obstante, los adolescentes regresarán a la ciudad antes de lo esperado debido a un corte en el camino de acceso al campamento, descubriendo que el resto de los habitantes de su población ha desaparecido. Las extrañas circunstancias que irán detectando los jóvenes tras su llegada les harán plantearse si realmente el resto de la población se ha desvanecido o si son ellos los que han sido trasladados a un universo paralelo.

De acuerdo con Heywood (2012), todas las personas son pensadores políticos, pues sean conscientes o no, utilizan ideas y conceptos políticos cuando expresan sus opiniones. Ejemplo de ello se encuentra en esta primera serie a analizar, The Society, en donde el grupo de adolescentes aislados del mundo comienza a discutir sobre qué forma de organización social desean para su nueva comunidad. Una serie que por su premisa evoca a The lord of the flies (El señor de las moscas) (William Golding, 1954), novela inglesa en la que un grupo de niños acaba sobreviviendo en una isla desierta sin compañía de adultos; y, ¿por qué escoger infantes para una 
historia política? Probablemente, porque Golding pensaba que los chicos, como seres semi-formados, podrían ser símbolos perfectos del conflicto central entre la civilización y la barbarie (Diken \& Laustsen, 2004). En este sentido, tanto los niños como los adolescentes están en pleno desarrollo de sus facultades cognoscitivas y sociales: "la adolescencia es una época de separación de los padres, de aprender a depender de uno mismo y de definir la identidad" (Myers, 2008, p. 27). En este caso específico, el grupo de la serie objeto de análisis debe aprender a trasladar ese aprendizaje a nivel exponencial: ¿qué sociedad van a definir? Así, los principales binomios que articulan al grupo de adolescentes se equilibran entre civilización o barbarie, orden o caos, y adultez o infancia.

¿Qué queremos como sociedad? ¿Qué conseguimos como grupo o como sujetos individuales con nuestras acciones? Son las primeras cuestiones que acechan a la comunidad de The Society una vez asimilado que no van a volver a la ciudad que conocen por un periodo de tiempo: ¿civilización o barbarie? Aquí, los conceptos de lo bárbaro y lo civilizado van a tener un significado específico. En este sentido, alejado del choque de civilizaciones propuesto por Huntington (2006), en este trabajo interesa la propuesta de Todorov (2008), quien expone que bárbaro es aquel que es cruel y feroz, la persona que niega la humanidad del contrario y que, por ello, le trata sin el más mínimo respeto por su integridad, física o moral. Por el contrario, la civilidad es aquel don que reconoce las diferencias del contrario y acepta su humanidad, tratándolo como tal, con respeto y comprensión. En síntesis, dos vertientes sobre la naturaleza humana que sirven de sustrato para las diferentes ideologías y cuyo cumplimiento interesa para detectar, o descartar, sus ramas.

Por tanto, sobre esta primera base, la naturaleza humana que expone la serie es conservadora, entendiendo que el conservadurismo considera que los seres humanos son esencialmente criaturas limitadas y que buscan seguridad, atraídas por lo conocido, lo familiar, lo probado (Heywood, 2012). Una vez solos en el universo, los chicos de la nueva sociedad intentan formar la estructura social conocida, entendiendo que las tradicionales instituciones ayudarán a preservar la moralidad de la nueva organización social. De acuerdo con Heywood (2012), la ideología conservadora entiende que la racionalidad humana no es fiable y la corrupción moral está implícita en cada individuo. En este marco, los adolescentes en The Society no se alojan en el extremo de menospreciar ferozmente a todo el diferente, pero la bondad intrínseca del ser humano defendida por el anarquismo (Goldman, 2008) no tiene cabida en esta narración. La violencia se intuye en el ambiente y sale a relucir en momentos claves: saqueos, asesinatos y sentencias a muerte. El miedo al desorden, por su parte, les hace tener la necesidad de un líder que los guíe por el camino. Una líder que planifica las jornadas de trabajo donde todos ayudan y que racionaliza los suministros alimenticios, hechos que hacen cuestionarse 
a los jóvenes si están viviendo una revitalización del socialismo. De acuerdo con Sotelo, el punto crucial del socialismo es "la satisfacción de las necesidades humanas" (2008, p. 94) donde prevalecen los intereses de la comunidad. Aquí, a priori, con las primeras iniciativas se aparenta cierta colectividad y solidaridad, pero el beneficio personal, piedra angular del capitalismo (Sotelo, 2008), no tarda en florecer. En este sentido, la separación entre los grupos de los privilegiados y la clase obrera-marginal del anterior mundo vuelve a surgir: aquellos que poseían más no consideran justo compartir sus pertenencias. La sociedad, consideran, se mantiene unida por los lazos de la tradición, la autoridad y una moralidad común (Heywood, 2012): el pasado importa, ellos deben restablecer el sistema social de sus padres, $\mathrm{y}$ también sus privilegios.

Homo homini lupus (el hombre es un lobo para el hombre), dijo Hobbes (1980): en un estado natural, la naturaleza del hombre le empuja a luchar contra sus prójimos. No obstante, a través de un contrato social se lograría armonizar las partes; un sistema que ponga orden y disciplina. Unas normas que ansían estos jóvenes, como dijo Campbell: "la democracia se la suda, solo quieren estar seguros" (Keyser \& Webb, 2019b, 39:52). Aquí, el gobierno es lo anhelado, no importan los fallos del anterior ni que pueda ser la causa de que se encuentren allí: el desorden es el desastre. En definitiva, la sociedad que plantean no vislumbra un horizonte muy halagüeño. En palabras de Golding, el hecho que prevalece es el intento de rastrear los defectos de la sociedad a partir de las deficiencias de la naturaleza humana (Golding, en Coy Girón, 1986).

¿Y qué rol juegan los elementos fantásticos en la caída y reconstrucción de esta sociedad? En The Society, los elementos naturales ligados a lo místico y no explicable aparecen en la ciudad con un doble objetivo. Por una parte, nos encontramos con una alteración de la naturaleza, tornándose lo natural en extraño dada su descontextualización. Las desviaciones de la naturaleza funcionan en la serie como un peligro o representación del mal externo al individuo (Lenne, 1974). De este modo, junto al olor nauseabundo y desconocido que asola la ciudad antes de la desaparición del resto de la población, los jóvenes de West Han son testigos de la anticipación de un eclipse solar no esperado hasta un lustro más tarde, o del ataque de animales peligrosos no presentes anteriormente en el bosque del municipio, específicamente de una serpiente venenosa que acaba con la vida de uno de los personajes. Los mencionados elementos actúan como indicadores de que algo no va bien en lo hasta ahora conocido, trascendiendo su dimensión orgánica y biológica para adquirir una dimensión simbólica. En este sentido, "las cosas, más que los indefensos humanos, son portadoras de valores, porque las sentimos, más que a la gente, como fuentes de poder" (Sontag, 2008, pp. 32-33). 
Es precisamente en esta ficción fantástica donde la irrupción de lo extraño actúa para este grupo de jóvenes como un espacio o tiempo para crecer hasta la adultez deseable (Waller, 2009). El enfrentamiento a la muerte, a la oscuridad o a lo desconocido son arrastrados por estos elementos, introduciendo la incertidumbre y la desestabilización del grupo de adolescentes. Sin embargo, en jóvenes más aventajados, como el personaje de Gordie, estos indicios detonan el cuestionamiento de su realidad y la posibilidad de encontrarse en un universo paralelo, iniciando un proceso de exploración e indagación sobre cómo regresar a casa bajo la creación de un comité específico para ello.

El enfrentamiento a esta experiencia se plantea en la serie no solo como una exploración del entorno e intento de comprensión de esta realidad paralela, sino también como un proceso de autoexploración de los límites y fortalezas de cada miembro del grupo. De esta forma, como señala María Luisa Rosenblat, basándose en la obra de autores clásicos del género como Poe o Cortázar, la naturaleza se concibe bajo una doble percepción:

el interior de la naturaleza exterior estáíntimamente relacionado con el interior de nuestra propia naturaleza, porque en nosotros y fuera de nosotros la naturaleza forma una unidad con lo Divino, raíz y fuente de fuerza creadora que en nosotros hace aflorar la conciencia de los pensamientos, y que fuera de nosotros hace surgir las cosas de la vida. (1997, p. 66)

Aplicado lo expresado por Rosenblat a la ficción analizada, una segunda apreciación con respecto a lo fantástico se observa dentro de la serie en las manifestaciones puntuales de lo divino, no con elementos sobrenaturales como visiones o milagros, sino a través de expresiones materiales: pintadas con versículos de la Biblia en edificios de poder dentro del pueblo (ayuntamiento e iglesia). Con la irrupción del mal olor, un primer versículo aparece pintado en letras rojas: “Te han pesado en la balanza y te falta peso" del libro de Daniel (Keyser \& Webb, 2019a, 51:49), anticipando que el misterioso fenómeno puede estar ligado a un juicio divino de la población de West Han, pero no siendo tomado en serio por los jóvenes que lo descubren, calificándolo de un mero grafiti realizado por alguien del municipio. Como señala Gloria Elena Betancur Jiménez (2016),

La caída de la religión, y con ello el desapego de los dogmas cristianos, lleva a la búsqueda de múltiples verdades que rijan los designios del hombre; no existe solo una respuesta para definir lo bueno y lo malo, el deber ser se modifica cuando se pasa de los designios de Dios, del deber para con Dios, a una racionalidad humana lejos de los principios religiosos y a una cultura sin Dios o con múltiples dioses. (2016, p. 111) 
En el primer episodio de The Society se manifiesta este desarraigo y pérdida de espíritu religioso en la juventud a través de la celebración de una fiesta en la iglesia la noche en que descubren que los adultos no están en el pueblo, quebrantando con ello los pilares más sagrados que sustentan su municipio. El peso ideológico de la religión en la serie es abordado a través del personaje de Helena, cuyo compromiso como creyente le lleva a sentirse en el deber de infundir esperanza y fortaleza al resto del grupo mediante sermones en la parroquia de la ciudad, introduciendo en este sentido sus ideas políticas sobre el líder que considera que debe ser apoyado por la mayoría. En el resto de los compañeros será el dilema moral, la revisión de los valores que priorizan y la dicotomía entre el binomio individualismo/bien común los principales ejes que sirvan como punto de partida para la reflexión ideológica dentro de la serie, como se ha detallado anteriormente.

Por último, la confrontación de estos ideales conformará la segunda vía de peligro manifestada por Lenne (1974): los peligros que vienen del hombre o que se vuelven contra él, de gran peso dentro de la lectura ideológica de la serie. En este sentido, The Society rescata patrones básicos dentro de lo Fantástico como la figura del "otro" y la detección de esta presencia en base al binomio bien vs. mal, considerándose malvado todo aquello que atente contra los valores establecidos o el orden social transgredido. De este modo, en The Society vemos un ejemplo de cómo el género fantástico ha generado unos mundos donde los adolescentes pueden experimentar una sensación de progresión o poder, pero donde al mismo tiempo estos se encuentran limitados por su naturaleza temporal, su ideología y su dependencia de la idea de normalidad (Waller, 2009).

\section{The Passage: el experimento científico al servicio del social-darwinismo}

Basada en la trilogía de libros homónima creada por Justin Cronin, The Passage aborda los límites de la experimentación científica a través del Proyecto NOAH, una instalación médica del gobierno de Estados Unidos. Este proyecto deriva del descubrimiento que realiza un grupo de doctores y médicos en una cueva de Bolivia de un ser milenario cuya sangre contiene la cura contra las enfermedades de las que la humanidad todavía no puede escapar (VIH, ébola, etc.). Al grupo protagonista, sin embargo, el destino no les guarda esa recompensa, pues algo no sale bien y la criatura se rebela contra ellos con un mordisco que inicia la creación de una nueva especie a través del denominado Paciente 0: Tim Fanning, neurólogo que lidera la expedición junto al Doctor Jonas Lear. Los científicos descubren que la inmortalidad tiene un precio: la humanidad. No obstante, este rodeo a la muerte resulta ser un anzuelo demasiado tentador $y$, con el objeto de obtener la recompensa sin tener que pagar un precio, el Proyecto NOAH utiliza la sangre de Fanning para comenzar una serie de experimentos con humanos de clases marginales y presos del corredor de la muerte que permita alcanzar la vida eterna sin secuelas: para examinar 
las causas de la vida, primero debemos recurrir a la muerte (Shelley, 2016). De esta forma, en The Passage se observa una reinterpretación de la obra de Shelley, donde Víctor Frankenstein juega con la ciencia y, en última instancia, temeroso ante el monstruo que había creado de la muerte, se niega a darle una compañera; tal ser abominable debe estar destinado a la soledad: el "ser" de Frankenstein se produce bajo unas relaciones socio-naturales particulares. Seguramente son esas relaciones, mezcladas, entretejidas y desordenadas las que deben llamar nuestra atención en Frankenstein y nos llevan a preguntarnos sobre qué tipo de sociedad queremos que sea producida (por quién, para qué propósitos y en qué condiciones) (Hammond, 2004).

Sin embargo, en The Passage el científico ambicioso no es una persona singular, sino una corporación gubernamental que, ansiosa por permanecer como primera potencia a nivel internacional, aparta los valores éticos y experimenta con humanos en busca de anticuerpos y armas biológicas. En este sentido, el primer objetivo deja de serlo cuando descubren que los anticuerpos pueden usarse como herramientas bélicas. Así, la creación de un remedio contra las enfermedades mortales que amenazan a la humanidad deja lugar a la creación de una nueva variante de ser humano, inmortal, con poderes telepáticos e invencible. De este modo, la naturaleza humana es observada desde una perspectiva liberal, donde los seres humanos son concebidos como criaturas egoístas y autosuficientes que no se encuentran condicionadas por el contexto sociohistórico (Heywood, 2012).

En esta línea, aunque en el discurso de The Passage salga a relucir en ciertas ocasiones el interés de crear unas condiciones generales mejores para toda la población, la dinámica de la trama gira en torno a intereses más egoístas: por ejemplo, la obsesión del científico jefe (Jonas Lear) por curar a su mujer enferma de alzhéimer. Una meta que incluso le hizo obviar las plegarias de su amigo infectado con el virus (Tim Fanning) y mantenerlo con vida en una jaula para observar su evolución. Además, la mecánica no cesa ahí, pues ligado a lo anterior cabe resaltar una variante específica del liberalismo que mantiene la serie: el social-darwinismo. ¿Por qué sobresale esta ideología? Esta cuestión se va respondiendo a lo largo de toda la primera temporada de la serie con las historias de los sujetos que sirven como conejillos de indias: personas repudiadas por el sistema que, por unos motivos u otros, se encuentran en centros penitenciarios esperando la inyección letal. Es en la utilización de los débiles de la sociedad donde se desarrolla uno de los rasgos más distintivos del liberalismo clásico; es decir, el menosprecio hacia la pobreza y la igualdad social. Cabe recordar que el liberalismo clásico mantiene un credo individualista y tiende a explicar las circunstancias sociales en términos de los talentos y el trabajo duro de cada ser humano (Heywood, 2012). 
La supervivencia del más fuerte, que se traduce en aquel que tenga más recursos económicos y, por tanto, más poder en la jerarquía social, una máxima que expresa Amy Bellafonte en su presentación: "Soy la niña de ninguna parte, por eso me eligieron” (Heldens, Ensler, \& Siega, 2019, 10:41). Así, el gobierno hace uso de los política y económicamente débiles del sistema para alcanzar sus ambiciosos objetivos: las desigualdades de riqueza, posición social y poder político son, por lo tanto, naturales e inevitables, y el gobierno no debe intentar interferir en ellas (Heywood, 2012). Es precisamente este énfasis en el gobierno como capaz de todo hasta las últimas consecuencias lo que hace más palpable la tónica del liberalismo clásico de donde surge el social-darwinismo en The Passage. Porque en esta rama el Estado, para funcionar eficazmente, debe limitarse a proteger los derechos de los individuos; es decir, protección sin intervención social, que puede llevar al despotismo (Rivero, 2008). Aquí se refleja hasta dónde es capaz de llegar un gobierno sin control que, en su obsesión por el Proyecto NOAH, pone en riesgo a todo el país y lo expone a bombas nucleares por países antiguamente aliados que ven en su pandemia un riesgo mortal. La conversión de Estados Unidos en la figura del "otro" repudiado a nivel internacional se expresa de forma manifiesta en la serie: "Es una crisis diplomática. El virus comenzó en Estados Unidos. Celebran reuniones y no nos invitan [la Organización Mundial de la Salud]" (Heldens \& Ensler, 2019b,10:44).

De este modo, a través de diez capítulos, los fallos individuales van dejando lugar a arrepentimientos y lazos humanitarios que son cortados por un gobierno déspota centrado en rentabilizar lo máximo posible sus inversiones, quedando en un segundo plano la consecuencia del proyecto. La protección que a priori parecía ofrecer se torna fácilmente en autoritarismo. De este modo, el trasvase del Proyecto NOAH de la Delegación de Sanidad al Departamento de Defensa estadounidense ofrece una confrontación de intereses entre varios personajes. Para Defensa, encarnado por el Secretario de Defensa Horace Guilder, las mutaciones vividas por los humanos del experimento son un resultado inesperado, pero positivo al que deben adaptarse y reevaluar para sacar la máxima rentabilidad al proyecto; para Sanidad, representada por la doctora Major Nichole Sykes y el científico Jonas Lear, estas mutaciones encarnan el fracaso de su investigación, generándoles el deber de revertir el horror creado y recuperar, por encima del coste económico, la naturaleza humana de esos pacientes.

Fruto de este proceso, se observa cómo el miedo generado por la experimentación científica también recae sobre los posibles efectos secundarios derivados de los productos e inventos desarrollados en este terreno. En The Passage, el resultado son unos pacientes humanos que han mutado física y psicológicamente hacia una nueva especie que denominan virales dentro del laboratorio, pero a 
los que diferentes personajes de la serie llaman vampiros dada su sensibilidad a la luz solar y a su deseo descontrolado por la sangre humana. En relación con esta mutación de los virales, la dualidad normalidad versus monstruosidad es planteada a través de este eje temático que aborda la generación de estos monstruos o bestias como consecuencia de esta manipulación científica; alteración de la naturaleza cuyo destino va vinculado a su exterminio u ocultación del orden establecido. Como señalan Bassa y Freixas, "el monstruo tiene como razón de ser la puesta en evidencia de las contradicciones de un orden aceptado por todos. Su no aceptación y mucho menos, integración, le aboca a su irremediable eliminación"; colmando de este modo los apetitos del espectador, "quien identifica al monstruo con el lado negativo y caótico tanto del ser humano como de la sociedad" (Bassa \& Freixas, 1993, pp. 46-47). La figura del monstruo provoca un enfrentamiento entre la normalidad y la anormalidad. Esta anormalidad se debe a su singularidad frente a la homogeneidad del grupo, siendo su integración dentro de la sociedad imposible, en tanto son mayores las diferencias que los rasgos comunes con lo que rígidamente se entiende por normal (Bassa \& Freixas, 1993). La dualidad provoca que también sea utilizado dentro del género para la representación del “otro", el ser perturbador de la cotidianeidad.

Las similitudes de los virales con la figura mítica del vampiro, ser protagónico de múltiples creaciones literarias, cinematográficas y televisivas que despierta «una profunda fascinación» en el público (Raya Bravo, 2014, p. 141), permite abordar otras cuestiones más imbricadas con la convivencia de lo humano y lo monstruoso en una misma criatura. Asimismo, se cuestionará quién es el monstruo dentro de esas instalaciones médicas. Como destaca Tim Fanning, el Paciente 0 del experimento, "los monstruos son los médicos que nos encierran [...]. Empezamos siendo víctimas, pero ahora somos afortunados” (Heldens \& Ensler, 2019a, 24:54). Con la última frase anticipa su plan de salir de las instalaciones gubernamentales para seguir propagando el virus, ampliando así la nueva especie de virales. En este sentido, el Paciente 0 adquiere un rol cuasi-divino, dado que de su sangre derivan el resto de los pacientes infectados, estableciendo en doce, como los Doce Apóstoles, el número de virales que necesita para poner en marcha su plan de fuga. Al contrario de los demás afectados, él fue infectado fuera del laboratorio, el Elegido para liderar esa nueva especie y, gracias a la mala praxis científica, ha ido ganando nuevos miembros con los que convivir y fortalecer su grupo.

En The Passage, a través de la figura del viral encontramos otra de las representaciones audiovisuales del personaje fantástico del vampiro. Según expresa Rosemary Jackson, frente a otras figuras simbólicas dentro de las producciones culturales como el zombi, el mito de Drácula "es mucho más difícil de «contener», mucho más perturbador en su estocada contracultural. No está confinado a un 
individuo: trata de reemplazar la vida cultural con una otredad total y absoluta, un sistema autosostenido completamente alternativo" (1981, pp. 56-57).

\section{DISCUSIÓN}

Existen varios rasgos de la televisión actual estadounidense que hacen de ella un caldo de cultivo perfecto para la preponderancia del género fantástico: la reinterpretación de las novelas literarias y la posibilidad de complejizar las tramas son dos de ellas (López Rodríguez, 2016, p. 16). En este estudio nos encontramos con estas dos premisas: el monstruo que se rebela contra su creador en The Passage, retornando la figura protagónica de un vampiro empoderado que no reniega de su nueva naturaleza y rechaza entrar de nuevo en el sistema del que formaba parte, y la creación de una sociedad desde cero en The Society, con el desafío que supone establecer unas normas de convivencia y control de los derechos y deberes de los habitantes de un mismo municipio. Dos historias que se complejizan en la narrativa audiovisual, entrelazando sus personajes con trasvases contemporáneos: la preocupación de una sociedad que sabe que se autodestruye, pero que no desea cambiar lo establecido. Así, la dualidad se manifiesta ideológicamente desentrañando las contradicciones del sistema: lo conocido contra lo extraño. El primero, aquel que con todos sus fallos es lo apropiado; lo segundo, aquello que provoca miedo y horror. En el caso de The Society, lo conocido y anhelado es la organización del gobierno en la que vivían con sus progenitores, ni mucho menos perfecta, pero ordenada y estable. Por parte de The Passage, lo extraño ataca directamente las estructuras sociales y las criaturas sobrenaturales creadas atentan contra el orden establecido y se rebelan contra un sistema que se estaba tornando autoritario. No obstante, en ambas series destaca la nostalgia por un pasado mejor, proveedor de calma y de tranquilidad.

De este modo, frente a otras series como Vampire Chronicles (The CW, 2009-2017) y siguiendo el relato de otras como True Blood (HBO, 2008-2014), en The Passage se observa a través de la figura de Tim Fanning una recuperación del vampiro como un outsider regido por sus propias normas, no siendo posible someterle de forma involuntaria a un proceso de aculturación o «movement of acculturation» (Derrida, 1995, p. 386) que equilibre su binomio invertido de anormalidad/normalidad. Mientras que en Vampire Chronicles la humanidad y los vampiros conviven armoniosamente e incluso los segundos desarrollan más valores comunitarios que en su vida humana (Santandreu Aranda, 2015), en True Blood el discurso se complejiza y las diversas realidades vampíricas (el consumo de sangre de humanos fallecidos, sintética o por la vía tradicional) enfrentan al espectador con sobre qué debe considerarse un derecho y cuál debe ser el proceso de aculturación con el "otro" 
(Wright, 2014). Al igual que en True Blood, en The Passage el vampiro es consciente de su naturaleza dual; pero al contrario de series como Buffy the Vampire Slayer (The WB, 1997-2003) o la ya mencionada Vampire Chronicles, donde prevalecen los valores solidarios (Wright, 2014; Raya Bravo, 2019), en The Passage los individuos (ya sean humanos o vampiros) se caracterizan por un individualismo egoísta y un afán competitivo por conseguir la superioridad sobre el "otro".

En The Society se observan igualmente las ansiedades compartidas dentro del género fantástico desde la década de 1950, como las catástrofes nucleares o los efectos derivados de la superpoblación y la falta de recursos para el mantenimiento de la humanidad (Memba, 2008, 2011). En específico, la serie adquiere un escenario postapocalíptico donde los adolescentes persiguen restaurar las instituciones anteriores al desastre sobrenatural, pero el mundo ya nunca será igual y el conflicto estalla entre los jóvenes. En palabras de Andrew Tate (2017), la ficción apocalíptica contemporánea es un reflejo de los deseos contradictorios de autodestrucción y supervivencia que atormentan al ser humano. La reflexión es compartida con otras series contemporáneas de temática apocalíptica y postapocalíptica como Jericho (CBS, 2006-2008) o The 100 (The CW, 2014-2020), ficciones que aprovechan sus escenarios desoladores para divagar sobre las nuevas convivencias a las que los grupos supervivientes se enfrentarían en situaciones extremas. En el caso de Jericho, la situación de crisis va unida a un mensaje conservador que mira con nostalgia hacia la América pastoral (Santaulària, 2014). En The 100, los problemas individuales de los supervivientes eclipsan el posicionamiento ideológico de la serie con la temática del armamento nuclear, que según señala Steven Holmes, es abordada con bastante indiferencia (2019). Con una premisa similar a The Leftlovers (HBO, 2014-2017), en The Society se produce una desaparición poblacional masiva inexplicable, y la repentina evaporación, según Tate (2017), es un evento divisorio, una ruptura temporal que no destruye la civilización, pero que aun así lo cambia todo. En la novela de Golding (1996), la violenta muerte de Piggy implicó, en términos de Todorov (2008), la victoria de lo bárbaro frente a lo humano; al igual que en The Society, el asesinato de Cassandra produjo que la ruptura temporal se convirtiera en permanente y que la solidaridad emergente de los primeros días postapocalípticos desapareciera para siempre de la nueva organización social.

En definitiva, las series de televisión pueden ofrecer vínculos con las ideas políticas (Nærland, 2020; Diken \& Laustsen, 2017). Específicamente, como señala Silva (2018), en el género de lo fantástico, al igual que en la realidad, los fenómenos extraños irrumpen generando situaciones de perplejidad que alteran el desarrollo "normal" de una sociedad. En este trabajo se ha corroborado que las narrativas fantásticas de The Society y The Passage invitan al individuo, y por extensión a la audiencia, a tomar conciencia del peso de su Yo en el mundo. Ante la sobrevenida 
de los fenómenos extraños, en The Society los jóvenes pueden asumir el reto de elegir otros pilares para la reconstrucción de la sociedad que comparten. Sin embargo, las instituciones y los valores tradicionales son los que adquieren un rol predominante en la nueva sociedad. La inversión del valor de lo individual frente a lo colectivo, por ejemplo, supone un conflicto con una parte de la población adinerada que desea recuperar el derecho a la propiedad privada. Como señala Julio López Saco, "[1]os denodados intentos de neutralizar la oposición engendrarán otras distinciones bipolares que reproducirán y harán perpetua la inicial" (2008, p. 98). La alteración de los elementos duales, salud/enfermedad, en el caso de The Passage, modifica el orden biológico establecido y engendra unas criaturas que son reflejo del horror del proyecto que las ha creado. Ambas series analizadas se encuentran permeadas por valores conservadores (respeto de las instituciones tradicionales y una percepción negativa de la naturaleza humana). No obstante, la figura de Amy Bellafonte en The Passage cuestiona la inmoralidad innata del ser humano y deja abierta la posibilidad de establecer unos criterios éticos sólidos que trasciendan lo exclusivamente monetario o armamentístico. Al contrario que en The Society, en The Passage el hombre no tiene por qué ser un lobo para el hombre.

\section{REFERENCIAS}

Barceló, M. (2015). Ciencia ficción. Nueva guía de lectura (Science fiction. New reading guide). Barcelona, Spain: Ediciones B.

Bassa, J. \& Freixas, R. (1993). El Cine de Ciencia Ficción. Una aproximación (The cinema of science fiction. An approximation). Barcelona, Spain: Paidós.

Batzke, I., Erbacher, E. C., Heß, L. M., \& Lenhardt, C. (2018). Exploring the fantastic. Genre, Ideology, and Popular Culture. Wetzlar, Germany: Transcript-Verlag.

Betancur Jiménez, G. E. (2016). La ética y la moral: paradojas del ser humano (Ethics and moral: Human being paradoxes). Revista CES Psicología, 9(1), 109-121. https://doi.org/10.21615/3482

Buonanno, M. (1999). El drama televisivo. Identidad y contenidos sociales (The television drama. Identity and social content). Barcelona, Spain: Gedisa.

Casetti, F. \& di Chio, F. (2010). Cómo analizar un film (How to Analyze a Film). Barcelona, Spain: Paidós.

Chillón, A. (2000). La urdimbre mitopoética de la cultura mediática (The Mythopoetic Warp of Media Culture). Anàlisi, (24), 121-159. Retrieved from https://www.raco.cat/index. php/analisi/article/view/15017

Chomsky, N. \& Herman, E. S. (2009). Los guardianes de la libertad: propaganda, desinformación $y$ consenso en los medios de comunicación de masas (Manufacturing Consent: The Political Economy of the Mass Media). Barcelona, Spain: Crítica.

Derrida, J. (1995). Points...Interviews, 1974-1994. Stanford, CA: Stanford University Press. 
Diken, B. \& Laustsen, C. B. (2006). From War to War: Lord of the Flies as the Sociology of Spite. Alternatives, 31(4), 431-452. Retrieved from http://www.jstor.org/stable/40645195

Diken, B. \& Laustsen, C. B. (2017). 'Life is a state of mind' - on fiction, society and Trump. Journal for Cultural Research, 21(3), 257-267. https://doi.org/10.1080/14797585.2017.1343027

Fernández, T. (2001). Lo real maravilloso de América y la literatura fantástica (The wonderful real of America and fantastic literatura). In D. Roas (Comp.), Teorías de lo fantástico (Theories of the fantastic) (pp. 283-297). Madrid, Spain: Arcos.

Galván Fajardo, E. (2007). Fundamentos básicos en la construcción del personaje para medios audiovisuales (Basic fundamentals in the construction of the character for audiovisual media). Enlaces, Revista del CES Felipe II, (7). Retrieved from http://hdl.handle.net/10016/5554

Geraghty, L. (2009). American Science Fiction Film and Television. Oxford, UK: Berg.

Girón, J. (1986). El terror del hombre moderno: Lord of the Flies (The Terror of Modern Man: Lord of the Flies).Atlantis, 8(1/2), 109-114. Retrieved from http://www.jstor.org/stable/41054539

Golding, W. (1996). El señor de las moscas (Lord of the flies). Madrid, Spain: Alianza editorial.

Goldman, E. (2008). La palabra como arma (Anarchism and Other Essays). Madrid, Spain: Tierra de Fuego.

Hammond, K. (2004). Monsters of modernity: Frankenstein and modern environmentalism. Cultural Geographies, 11(2), 181-198. Retrieved from http://www.jstor.org/stable/44250971

Heldens, L. (Writer) \& Ensler, J. (Director). (2019a). I Want To Know What You Taste Like (Season 1, Episode 6) (TV series episode). In L. Heldens, M. Reeves, R. Scott, D. W. Zucker, A. Kassan, \& J. Ensler (executive producers), The Passage. 20th Century Fox Television; 6th \& Idaho; Selfish Mermaid; Scott Free Productions.

Heldens, L. (Writer) \& Ensler, J. (Director). (2019b). Last Lesson (Season 1, Episode 10) (TV series episode). In L. Heldens, M. Reeves, R. Scott, D. W. Zucker, A. Kassan, \& J. Ensler (executive producers), The Passage. 20th Century Fox Television; 6th \& Idaho; Selfish Mermaid; Scott Free Productions.

Heldens, L. (Writer), Ensler, J., \& Siega (Directors). (2019). Pilot (Season 1, Episode 1) (TV series episode). In L. Heldens, M. Reeves, R. Scott, D. W. Zucker, A. Kassan, \& J. Ensler (executive producers), The Passage. 20th Century Fox Television; 6th \& Idaho; Selfish Mermaid; Scott Free Productions.

Heywood, A. (2012). Political Ideologies: An Introduction. UK: Palgrave Macmillan.

Hobbes, T. (1980). Leviatán (Leviathan). Madrid, Spain: Madrid Editora Nacional.

Holmes, S. (2019). From The Day After to The 100: Nuclear Weapons on Television. Studies in the Fantastic, 6(1), 70-94. https://doi.org/10.1353/sif.2018.0003

Huici, A. (1996). Estrategias de la persuasión: mito y propaganda política (Persuasion Strategies: Myth and Political Propaganda). Sevilla, Spain: Alfaguara.

Huntington, S. P. (2006). El choque de civilizaciones y la reconfiguración del orden mundial (The Clash of Civilizations and the Remaking of World Order). Barcelona, Spain: Paidós.

Jackson, R. (1981). Fantasy: literatura y subversión (Fantasy: The Literature of Subversion). Buenos Aires, Argentina: Catálogos Editora. 
Jenkins, H. (2000). Reception theory and audience research: the mystery of the vampire's Kiss. In C. Gledhill \& L. Williams (Eds.), Reinventing Film Studies (pp. 8-17). UK: Bloomsbury.

Johnson-Smith, J. (2005). American Science Fiction Tv: Star Trek, Stargate and Beyond. London, UK: I.B. Tauris.

Kallas, C. (2014). Inside The Writers' Room: Conversations with American TV Writers. Londres, UK: Palgrave.

Keyser, C. (Writer) \& Webb, M. (Director). (2019a). What Happened (Season 1, Episode 01.) (TV series episode). In M. Webb (executive producer), The Society. Netflix. http://www.netflix.com

Keyser, C. (Writer) \& Webb, M. (Director). (2019b). How it Happens (Season 1, Episode 10.) (TV series episode). In M. Webb (executive producer), The Society. Netflix. http://www.netflix.com

Lenne, G. (1974). El cine fantástico y sus mitologías (Fantastic cinema and its mythologies). Barcelona, Spain: Anagrama.

López Rodríguez, F. J. (2016). The intertextual monstrous. Appropriations of Frankenstein in the era of Quality Television. Brumal. Revista de investigación sobre lo Fantástico, 4(1), 57-78. https://doi.org/10.5565/rev/brumal.282

López Saco, J. (2008). Personificaciones mítico-simbólicas del concepto filosófico Yin-Yang en China (Personifications Mythic-symbolic of the Philosophical Concept of Yin-Yang in China). Lógoi Revista de Filosofía, (14), 97-107. Retrieved from http://revistasenlinea.saber. ucab.edu.ve/temas/index.php/logoi/article/view/647/635

Loshitzky, Y. (1996). Travelling culture/travelling television. Screen, 37(4), 323-335. https://doi.org/10.1093/screen/37.4.323

Martel, F. (2011). Cultura mainstream. Cómo nacen los fenómenos de masas (Mainstream culture. How mass phenomena are born). Barcelona, España: Taurus.

Memba, J. (2008). La edad de oro de la ciencia ficción (1950-1968) (The Golden Age of Science Fiction (1950-1968)). Madrid, Spain: T \& B editores.

Memba, J. (2011). La nueva era del cine de ciencia ficción (1971-2011) (The New Era of Science Fiction Cinema (1971-2011)). Madrid, Spain: T \& B editores.

Myers, D. (2008). Psicología social (Social psychology). Mexico City, Mexico: McGrawHill.

Nærland, T. U. (2019). Fictional Entertainment and Public Connection: Audiences and the Everyday Use of TV-series. Television \& New Media, 20 (7), 651-669. https://doi.org/10.1177/1527476418796484

Nogueira Ramos Neto, J. A. \& Marcio Markendorf, M. (2018). Cinema da peste: a epidemia como metáfora de disfuncionalidades sociais nos filmes-catástrofe (Plague cinema: the epidemic as a metaphor for social dysfunctions in catastrophe films). In F. García, C. Reis, A. C. dos Santos, M. C. Batalha, J. França, \& R. Michelli (Orgs.), A personagem nos mundos possíveis do insólito ficcional. Anais com Comunicações em Simpósios (The character in the possible worlds of the fictional unusual. Proceedings with Communications at Symposia) (pp. 365-374). Rio de Janeiro, Brazil: Dialogarts. 
Nye, J. S. (2005). Soft Power: The Means To Success In World Politics. New York, NY: Public Affairs.

Pérez de Algaba Chicano, C. \& Rubio-Hernández, M. M. (2015). La dualidad del serial killer. Análisis de la presencia del doble a través de sus patrones relacionales (The duality of the serial killer. Analysis of the presence of the double through its relational patterns). In A. Hermida \& V. Hernández-Santaolalla (Coords.), Asesinos en serie(s). Representación persuasiva del serial killer en la ficción televisiva contemporánea (Serial killers(s). Persuasive representation of the serial killer in contemporary television fiction) (pp. 173-190). Madrid, Spain: Síntesis.

Pineda, A., Fernández-Gómez, J. D., \& Huici, A. (2018). Introducción: hacia un estudio sistemático de las ideologías políticas en la cultura de masas (Introduction: towards a systematic study of political ideologies in mass culture). In A. Pineda, J. D. FernándezGómez, \& A. Huici (Coords.), Ideologías políticas en la cultura de masas (Political ideologies in mass culture) (pp. 11-20). Madrid, Spain: Tecnos.

Raya Bravo, I. (2019). Buffy Summers. La defensa heroica de la vida cotidiana (Buffy Summers. The heroic defense of everyday life). In I. Raya-Bravo (Coord.), El viaje de la heroina. 10 iconos femeninos épicos del cine y la televisión (The journey of the heroine. 10 epic female icons from film and television) (pp. 71-80). Sevilla, Spain: ReaDuck.

Raya Bravo, I. (2014). True Blood, el fin del vampiro como ser metafórico (True Blood, the end of the vampire as a metaphorical being). Frame, (10), 139-143. Retrieved from http://fama2.us.es/fco/frame/frame10/monografico3/5.7.pdf

Rivero, Á. (2008). Liberalismo conservador (de Burke a Nozick) (Conservative liberalism (from Burke to Nozick)). In J. A. Mellón (Ed.), Ideologías y movimientos políticos contemporáneos (Contemporary political ideologies and movements) (pp. 45-62). Madrid, Spain: Tecnos.

Santandreu Aranda, A. (2015). Myss Mystic 2.0. The Vampire Diaries' Caroline Forbes and the American Dream: With and Without Fangs. Oceánide, (7). Retrieved from https://oceanide.es/index.php/012020/article/view/12/93

Santaularia, I. (2014). “There's some things apocalypse can't change”: Gender in Jericho. In P. Gallardo \& E. Russell (Eds.), Yesterday's Tomorrows: On Utopia and Dystopia (pp. 99-121). Newcastle, UK: Cambridge Scholars Publishing.

Silva, I. B. da. (2018). A realidade sob ameaça: conexões entre o fantástico, a alegoria e a história (The reality under threat: connections between the fantastic, allegory and history). Mosaico, 17(1), 141-160.

Rosenblat, M. L. (1997). Lo fantástico y detectivesco. Aproximaciones comparativas a la obra de Edgar Allan Poe (The fantastic and detective. Comparative approaches to the work of Edgar Allan Poe). Venezuela: Monte Ávila Editores Latinoamericana.

Scott, M., Street, J., \& Inthorn, S. (2011). From entertainment to citizenship: A comparative study of the political uses of popular culture by first-time voters. International Journal of Cultural Studies, 14(5), 499-514. https://doi.org/10.1177/1367877910394568

Seed, D. (2011). Science Fiction. A Very Short Introduction. Oxford, UK: Oxford University Press. Shelley, M. (2016): Frankenstein. London, UK: Arcturus.

Sontag, S. (2008). La imaginación del desastre (The imagination of disaster). In A. J. Navarro (Coord.), El cine de ciencia ficción: explorando mundos (Science fiction cinema: exploring worlds) (pp. 21-49). Madrid, Spain: Valdemar. 
Sotelo, I. (2008). Socialismo (Socialism). In J. A. Mellón (Ed.), Ideologías y movimientos políticos contemporáneos (Contemporary political ideologies and movements) (pp. 79-100). Madrid, Spain: Tecnos.

Tate, A. (2017). Apocalyptic Fiction. India: Bloomsbury.

Telotte, J. P. (2008). The Essential Science Fiction Television Reader. Kentucky, KY: The University Press of Kentucky.

Telotte, J. P. (2014). Science Fiction TV. New York, NY: Routledge.

Todorov, T. (2008). El miedo a los bárbaros (The Fear of Barbarians). Barcelona, Spain: Galaxia Gutemberg.

van Dijk, T. (2000). Ideología: un enfoque multidisciplinario (Ideology: a multidisciplinary approach). Barcelona, Spain: Gedisa.

van Dijk, T. (2009). Discurso y poder. Contribuciones a los Estudios Críticos del Discurso (Discourse and Power). Barcelona, Spain: Gedisa.

van Zoonen, L. (2007). Audience Reactions to Hollywood Politics. Media, Culture \& Society, 29(4), 32-547. https://10.1177/0163443707076188

Vax, L. (1965). Arte y literatura fantásticas (Fantastic art and literatura). Buenos Aires, Argentina: Eudeba.

Waller, A. (2009). Constructing Adolescence in Fantastic Realism. New York, NY: Routledge.

Wodak, R. (2003). De qué trata el análisis crítico del discurso (ACD). Resumen de su historia, sus conceptos fundamentales y sus desarrollos (What is critical discourse analysis (ACD) about? Summary of its history, its fundamental concepts and its developments). In R. Wodak \& M. Meyer (Comps.), Métodos de análisis crítico del discurso (Critical discourse analysis methods) (pp. 17-34). Barcelona, Spain: Gedisa.

Wright, L. (2014). Post-vampire: The politics of Drinking Humans and Animals in Buffy the Vampire Slayer, Twilight, and True Blood. Journal of the Fantastic in the Arts, 25(2/3), 347-365. Retrieved from https://www.jstor.org/stable/i24353022 


\section{SOBRE LAS AUTORAS}

MAYTE DONSTRUP, Personal Investigador en Formación (VI Plan Propio US) en el Departamento de Comunicación Audiovisual y Publicidad de la Universidad de Sevilla, donde realiza su labor docente e investigadora en el seno del grupo de investigación IDECO. Actualmente se encuentra trabajando en su tesis sobre recepción, distopía e ideología. Sus principales líneas de investigación se focalizan en los estudios de recepción, ideologías en la cultura de masas, y en estudios de comunicación política.

iD http://orcid.org/0000-0001-6236-4967

CRISTINA ALGABA, licenciada en Comunicación Audiovisual y doctoranda dentro del programa de Doctorado Interuniversitario de Comunicación organizado por las universidades de Sevilla, Málaga, Huelva y Cádiz. Es miembro de IDECO (SEJ-539), grupo de investigación en comunicación política, ideología y propaganda del Departamento de Comunicación Audiovisual y Publicidad de la Universidad de Sevilla, donde también ha ejercido como asistente honoraria y docente. Sus principales líneas de investigación se centran en la ficción televisiva, reciclaje audiovisual, ideología y estudios culturales. 